\title{
BMJ Open Motivational interviewing with community-dwelling older adults after hip fracture (MIHip): protocol for a randomised controlled trial
}

\author{
Nicholas F Taylor (D) , ,2 Paul D O'Halloran (D) , ' Jennifer J Watts (D) , ${ }^{3}$ \\ Rebecca Morris, ${ }^{2,4}$ Casey L Peiris (D) , 'Judi Porter (D) , ${ }^{5}$ Luke A Prendergast (D) , \\ Katherine E Harding (ID) ,1,2 David A Snowdon (1) ,",7 Christina L Ekegren (1) , 8,9 \\ Raphael Hau (D) , ${ }^{10}$ Shalika B Mudiyanselage (1) , ${ }^{3}$ Made U Rimayanti, ${ }^{1,2}$ \\ Kate E Noeske, ${ }^{7}$ Megan Snowdon, ${ }^{7}$ Daniel Kim, ${ }^{2}$ Nora Shields (D) ${ }^{1}$
}

To cite: Taylor NF,

O'Halloran PD, Watts JJ, et al. Motivational interviewing with community-dwelling older adults after hip fracture (MIHip): protocol for a randomised controlled trial. BMJ Open 2021;11:e047970. doi:10.1136/ bmjopen-2020-047970

- Prepublication history and additional supplemental material for this paper are available online. To view these files, please visit the journal online (http://dx.doi.org/10.1136/ bmjopen-2020-047970).

Received 15 December 2020 Accepted 20 May 2021

Check for updates

(C) Author(s) (or their employer(s)) 2021. Re-use permitted under CC BY-NC. No commercial re-use. See rights and permissions. Published by BMJ.

For numbered affiliations see end of article.

Correspondence to Professor Nicholas F Taylor; n.taylor@latrobe.edu.au

\section{ABSTRACT}

Introduction Community-dwelling people recovering from hip fracture have the physical capacity to walk in their community but lack the confidence to do so. The primary aim of this trial is to determine whether motivational interviewing increases time spent walking at 12 months in community-dwelling people after hip fracture compared with an attention placebo control group. Secondary aims are to evaluate cost effectiveness, patient and health service outcomes and to complete a process evaluation. Methods and analysis An assessor-blinded parallel group randomised controlled design with embedded health economic evaluation and process evaluation will compare the effects of $n=270$ participants randomly allocated to an experimental group (motivational interviewing) or a control group (dietary advice). For inclusion, participants are aged $\geq 65$ years, living at home independently within 6 months of discharge from hospital after hip fracture and able to walk independently and communicate with conversational English. Key exclusion criteria are severe depression or anxiety, impaired intellectual functioning and being medically unstable to walk. Participants allocated to the experimental group will receive 10 (8 weekly and 2 booster) telephone-based sessions of motivational interviewing to increase walking over 16 weeks. Participants allocated to the control group will receive an equivalent dose of telephone-based dietary advice. The primary outcome is daily time spent walking over 7 days assessed at weeks 0, 9, 26 and 52 . Secondary outcomes include measures of psychological-related function, mobility-related function, community participation, healthrelated quality of life and falls. Health service utilisation and associated costs will be assessed. Process evaluation will assess the fidelity of the motivational interviewing intervention and explore contextual factors through semistructured interviews.

Ethics and dissemination Ethical approval obtained from Eastern Health (E19-002), Peninsula Health (50261/ EH-2019), Alfred Health (617/20) and La Trobe University (E19/002/50261). The findings will be disseminated in peer-reviewed journals, conference presentations and public seminars.

\section{Strengths and limitations of this study}

- This trial is an adequately powered randomised controlled trial which controls for the attention component of intervention.

- A health economic cost effectiveness analysis will be completed alongside the trial.

- A process evaluation of intervention fidelity, contextual factors affecting outcomes and causal mechanisms will be completed alongside the trial.

- During restrictions due to COVID-19, outcome measures requiring face-to-face assessment such as clinician-observed mobility-related function cannot be completed on all participants.

Trial registration number ACTRN12619000936123.

\section{INTRODUCTION}

Hip fracture is a common and serious injury affecting older Australians. Each year in Australia at least 23000 older adults will fracture their hips. ${ }^{1}$ Hip fractures have serious health consequences. Mortality rates at 12 months are in excess of $20 \% .{ }^{23}$ For survivors of hip fracture, ongoing disability is a major problem. People with hip fracture are three times more likely to be re-hospitalised compared with patients receiving elective hip surgery. ${ }^{4}$ Only $65 \%$ of people living at home at the time of their fracture are able to return home after fracture. ${ }^{2}$ As few as $40 \%$ of people return to their prefracture level of walking ${ }^{5}$ and only half of people who were able to walk outdoors before their fracture can do so afterwards. ${ }^{6}$ More than half of patients who return home after hip fracture fall within 12 months. ${ }^{7}$ These people report substantially 
reduced levels of walking at home and in the community ${ }^{8}$ and reduced confidence in their walking. ${ }^{89}$

Rehabilitation aims to promote functional independence to prepare patients to return to living in the community. After hip fracture surgery, clinical practice guidelines recommend patients be offered a coordinated multidisciplinary rehabilitation programme. ${ }^{10}{ }^{11}$ These rehabilitation programmes emphasise discharge planning, restoring patients' physical capacity to walk and ensuring they achieve functional independence in selfcare tasks necessary to live independently in the community. ${ }^{112}$ A systematic review of 19 randomised trials focusing on physical interventions in older adults after hip fracture concluded there is insufficient evidence to establish the best strategies for enhancing mobility after hip fracture surgery, because existing trials are underpowered and at high risk of bias. ${ }^{13}$ Therefore, adequately powered trials assessing interventions to increase mobility after hip fracture are required.

Lack of physical activity is associated with poor health outcomes and is the fourth leading risk factor for global mortality, accounting for $6 \%-9 \%$ of all deaths. ${ }^{14}{ }^{15}$ For people with hip fracture, walking is an appropriate means of participating in physical activity. ${ }^{1617}$ To improve health, the promotion of physical activity in the form of walking is a significant public health initiative across the lifespan, including for older people. ${ }^{18}$ Dose-response effects for the benefits of physical activity have been demonstrated. People who complete planned physical activity (ie, exercise) for as little as 15 min per day have a $14 \%$ reduced risk of all-cause mortality and a 3-year longer life expectancy than those who are inactive. ${ }^{15}$ Increasing physical activity levels by $10 \%$ in Australia would result in an estimated 2000 fewer deaths, 25000 fewer lost years of healthy life due to disability and \$A96 million reduction in health sector costs. ${ }^{19}$ Guidelines recommend older adults who are limited by health conditions be 'as physically active as their functional ability allows'. ${ }^{20}$

People are sedentary after hip fracture and participate in low amounts of walking during rehabilitation and recovery. ${ }^{21}$ Acute and subacute hospital stays after hip fracture are characterised by markedly reduced levels of walking. ${ }^{22} 23$ Two-months after hip fracture, walking levels remain low, with patients averaging 1082 steps/ day, ${ }^{24}$ compared with the recommended 7100 steps/day for older adults ${ }^{25}$ and 7500 steps/day for reductions in mortality in older women. ${ }^{26}$ Around 6 months after hip fracture, community-dwelling older adults have low levels of walking activity (median 2468-4439 steps/day). ${ }^{27} 28$ This suggests there is no natural return to pre-existing physical activity levels and walking after discharge home; a finding consistent with patient reports. ${ }^{8}$ Furthermore, sustained sedentary behaviour after hip fracture increases the risk of a second hip fracture by $88 \% .^{29}$

After hip fracture, community-dwelling older adults are often able to complete walking tasks reflective of community walking, such as walking continuously for 315 $\mathrm{m}$, walking up and down kerbs, and crossing a road at sufficient speed. ${ }^{9}$ They are also able to tolerate prescribed levels of moderate-intensity physical activity ${ }^{16}$ expected to confer health benefits. ${ }^{15}$ However, community-dwelling older adults with hip fracture perceive substantial restrictions in mobility and experience low levels of confidence in walking outside their home. ${ }^{9}$ Fear of falling has also been reported to impede functional recovery and, along with reduced self-efficacy, can prevent outdoor walking in community-dwelling people after hip fracture. . $^{30-32}$ Despite this, physical training for mobility and self-care tasks is the main focus during rehabilitation, with insufficient focus on psychological support. ${ }^{12}$ Focusing rehabilitation efforts on improving physical capacity to walk and completing self-care tasks, without addressing psychological barriers to walking, may not adequately prepare people to return to living and participating in their community after hip fracture.

Interventions that provide psychological support may address the sedentary behaviour and reduced walking observed in community-dwelling adults after hip fracture. ${ }^{33}$ Motivational interviewing is a behaviour change technique that has a specific focus on increasing confidence, ${ }^{34}$ and could therefore be useful for increasing physical activity in people after hip fracture. Motivational interviewing has been shown, via a large meta-analysis, to lead to health behaviour change in non-hip fracture populations. ${ }^{35}$ Another meta-analysis of trials that confirmed treatment fidelity showed that motivational interviewing led to significant increases in physical activity among people with chronic health conditions. ${ }^{36}$

As a precursor to the proposed randomised controlled trial, we piloted a motivational interviewing intervention in 30 community-dwelling older adults after hip fracture. ${ }^{37}$ Participants were randomly allocated to a usual-care control group $(n=15)$ or an experimental group $(n=15)$. The experimental group received eight 30-minute weekly sessions of motivational interviewing by telephone from a trained allied health professional. Relative to usual care without telephone calls, at week 9 the motivational interviewing group spent more time walking per day (mean difference $14 \mathrm{~min}, 95 \%$ CI 1 to 29), took more steps per day (mean difference 1237 steps, 95\% CI 12 to 2463), and were more confident about walking and about not falling. However, it is unknown whether these benefits are sustained over a longer period, whether they are cost effective, and whether the results might be explained by the experimental group receiving more attention.

We hypothesise that telephone-based motivational interviewing will increase walking in community-dwelling older adults after hip fracture compared with a control intervention of nutritional education (figure 1). Our primary aim is as follows:

1. To determine whether motivational interviewing increases time spent walking in community-dwelling people 12 months after hip fracture compared with an attention placebo control group receiving nutritional education.

The secondary aims are as follows: 


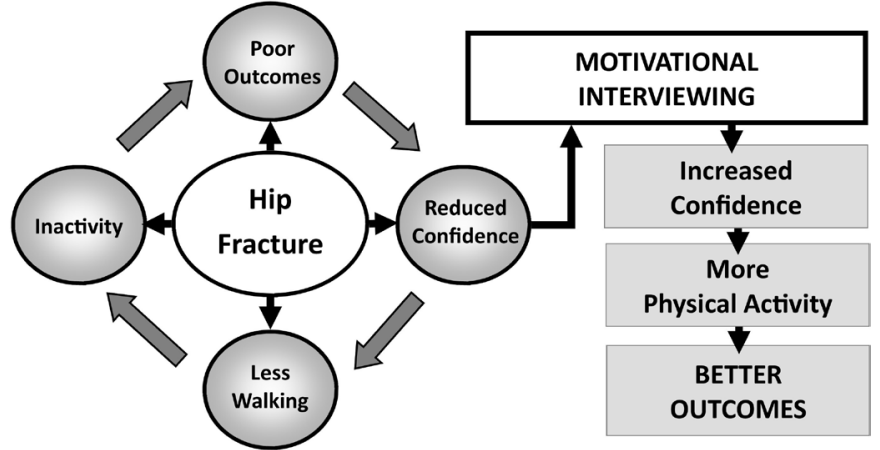

Figure 1 Trial rationale.

1. To determine whether motivational interviewing improves mobility-related function, physical activity, community participation and psychological outcomes, and reduces falls and hospital readmissions compared with an attention placebo control group.

2. To complete a health economic analysis to determine the cost effectiveness of motivational interviewing for community-dwelling people after hip fracture.

3 . To complete a process evaluation to determine intervention fidelity, to explore the causal mechanism of any effect and to explore factors associated with variation in outcomes.

\section{METHODS AND ANALYSIS}

\section{Trial design}

We will complete a multisite, assessor-blinded, parallelgroup, randomised controlled trial (figure 2) with oneto-one allocation ratio. The trial will include a process evaluation and a health economic evaluation. The trial will be conducted at three large health networks in metropolitan Melbourne, Australia. Participants will be randomly allocated to an experimental group receiving motivational interviewing or to an attention placebo control group receiving health education about nutrition using permuted blocks stratified for site (health service) and sex. Participants will be randomly assigned remotely using a permuted block design with a computer random number generator prepared by a researcher independent of the research team. Allocation will be determined by email contact with the independent researcher after the member of the research team has determined eligibility for the trial, participants have consented to take part and baseline assessment has been completed. Outcomes will be collected in a blinded fashion. Owing to the nature of the intervention being tested, full blinding of participants to intervention group allocation will not be possible. Data analysts will be blinded to group allocation. The trial has been registered prospectively, including updates, with the Australian and New Zealand Clinical Trial Registry (online supplemental appendix 1).

Figure 2 Trial design.

Recruitment: Community-dwelling people after hip fracture

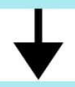

Measure: Community walking, self-efficacy, mobility, falls, participation, health-related quality of life, and health utilisation

Experimental $(n=135)$

Motivational Interviewing

8 weekly sessions
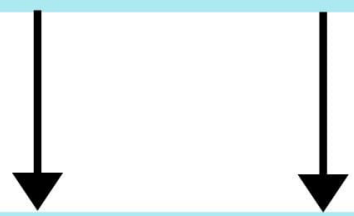

Attention placebo control $(n=135)$

Nutritional education

8 weekly sessions

Measure: Community walking, self-efficacy, mobility, falls, participation, and health-related quality of life

\section{Motivational Interviewing}

2 booster sessions

Measure: Community walking, self-efficacy, mobility, falls, participation, health-related quality of life, and health utilisation

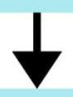

Measure: Community walking, self-efficacy, mobility, falls, participation, health-related quality of life, and health utilisation and cost
Nutritional Education

2 booster sessions 


\section{Participants}

Participants will be included if they had a hip fracture (S72.0-S72.2 according to the International Classification of Diseases 10th revision); live at home independently; are aged $\geq 65$ years; have been discharged from hospital within the last 6 months; are able to walk independently with or without an assistive device; can communicate with conversational English and are insufficiently active (defined as participating in $<150$ min of moderate-intensity physical activity per week $)^{20}$ as screened by accelerometers.

Participants will be excluded if they score in the severe range of depression or anxiety as measured by the Depression Anxiety and Stress Scale ${ }^{38}$ because they would require high-level psychological support; score $>2$ errors on the 10-item Short Portable Mental Status Questionnaire indicative of impaired intellectual functioning ${ }^{39}$; are medically unstable to walk based on a pre-exercise screening questionnaire ${ }^{40}$ and are unable to converse over the telephone (eg, due to hearing loss). The criteria of conversational English and cognitive capacity will ensure participants can engage in motivational interviewing conversations.

\section{Recruitment}

A representative of each health network will monitor discharges of potential participants using health network reports. Initial contact with a potential participant will be made by telephone or in person from a representative of the health network. If the participant agrees, their details will be forwarded to a research team member, who contacts the potential participant either in person at their home (after completion of a home visit risk screen assessment tool) or by telephone based on their preference, provides a copy of the Participant Information Sheet and fully explains the trial. The participant will be given the opportunity to make another appointment before providing written informed consent if they wish to consider their participation or discuss their participation with their family and or general practitioner.

\section{Intervention}

All participants will receive standard care in the community during the trial. This may involve participants attending their general practitioner, community groups or a physiotherapist. The content of standard care will be documented for all participants.

The experimental group will receive telephone-based motivational interviewing (table 1). Motivational interviewing is a directive style of communication aligned with behavioural change theories such as the transtheoretical model of change and self-determination theory. ${ }^{41}{ }^{42}$ The health professional delivering the intervention works collaboratively with the participant to assist them to increase their motivation to change their behaviour, in this case walking. ${ }^{34}$ This is done through a process of participants forming their own arguments for change and building their confidence for change. In this trial, motivational interviewing will address issues

Table 1 Description of experimental and control group interventions

\begin{tabular}{|c|c|c|}
\hline & Experimental group & Control group \\
\hline Why & Build confidence to increase walking behaviour & Provide nutritional education \\
\hline Who provided & $\begin{array}{l}\text { Allied health professional who has received training } \\
\text { in motivational interviewing by attendance at a 2-day } \\
\text { workshop and one-on-one coaching from an expert } \\
\text { motivational interviewing practitioner }\end{array}$ & Accredited practising dietitian \\
\hline When/how much (dose) & $\begin{array}{l}10 \text { sessions each of } 30 \text { min duration over } 16 \text { weeks } \\
\text { (total } 5 \text { hours) }\end{array}$ & $\begin{array}{l}10 \text { sessions each of } 30 \text { min duration over } \\
16 \text { weeks (total } 5 \text { hours) }\end{array}$ \\
\hline Tailoring & $\begin{array}{l}\text { Sessions tailored to the needs and progress of the } \\
\text { individual }\end{array}$ & $\begin{array}{l}\text { Sessions tailored to the need and } \\
\text { progress of the individual }\end{array}$ \\
\hline Fidelity checking measures & $\begin{array}{l}\text { Fidelity assessed with Motivational Interviewing } \\
\text { Integrity Scale on a sample of audiotaped sessions } \\
\text { Adherence through number of completed sessions } \\
\text { and duration of session from clinician logbook }\end{array}$ & $\begin{array}{l}\text { Fidelity assessed by review of a sample of } \\
\text { audiotaped sessions } \\
\text { Adherence through number of completed } \\
\text { sessions and duration of session from } \\
\text { clinician logbook }\end{array}$ \\
\hline
\end{tabular}


associated with ambivalence about change in walking, such as beliefs about physical activity and walking, low confidence, and fear of falling that may prevent people from walking more after hip fracture. There will be one session weekly for the first 8 weeks, each approximately 30 min of duration. The content of sessions will follow the recommended process of engagement, focusing, evoking and planning. ${ }^{34}$ Sessions 1 and 2 will focus primarily on introduction and participant engagement, while sessions 3-8 will focus on increasing confidence about walking. Participants will receive two booster sessions focusing on maintenance of behavioural changes and confidence in walking behaviour in weeks 12 and 16 . The schedule of motivational interviewing sessions is designed to provide an optimal dose of 5 hours. ${ }^{43}$

The intervention will be delivered after participants have been discharged home from hospital to enable the motivational interviewing discussions to be contextualised to daily life. Also, withdrawal of supports from the health service can be a critical time for successful recovery; a time when physical activity levels and confidence are low. ${ }^{9}{ }^{2737}$ The intervention will be delivered by an allied health professional trained in motivational interviewing, through attendance at a 2-day workshop and one-on-one coaching from an expert motivational interviewing practitioner. The allied health professional's proficiency and fidelity in using motivational interviewing (intervention fidelity) will be confirmed through audiorecording of all motivational interviewing sessions, and analysis of a randomly selected sample of $20 \%$ of these sessions by an independent trained assessor using the validated Motivational Interviewing Integrity Scale (MITI), V.4.2.1. ${ }^{44}$

To account for the attention component of motivational interviewing, participants allocated to the attention placebo control group will also receive 10 telephone calls of comparable duration comprising health education from an accredited practising dietitian. Health education will focus on nutritional education (dietary assessment and intervention) as nutrition is an issue for all older people after hip fracture. ${ }^{45}$ A nutritional education intervention has been demonstrated to be feasible after hip fracture, ${ }^{46}$ and credible as it has been successfully applied as a placebo attention control in a trial with this population. ${ }^{47}$ The content of the telephone calls will be benign, and not expected to have any effect on walking confidence or physical activity. A small number of sessions will be audiorecorded for each participating dietitian. The fidelity of nutritional education will be assessed and the presumed lack of proficiency in motivational interviewing assessed using MITI, V.4.2.1.

\section{Outcomes}

Outcomes will be measured at weeks $0,9,26$ and 52 (table 2). Assessors will be $\mathrm{f}$ blinded to group allocation and experienced in musculoskeletal evaluation. Assessments can be completed at the participant's home, or over the telephone, as appropriate, with the option to make an appointment for assessment at the health service. Owing to COVID-19, all assessments since March 2020 have been completed by telephone and this will continue until it is deemed safe to recommence face-to-face assessments.

\section{Primary outcome measure}

Walking: A tri-axial accelerometer-based activity monitor (activPAL) will be used to objectively measure the primary endpoint of walking (daily time in minutes spent walking) completed inside and outside the home. The activPAL is a valid and reliable measure of physical activity in community dwelling older adults. ${ }^{48}$ It can detect hypothesised increases in walking for people recovering from hip fracture, providing evidence of construct validity. ${ }^{37} 49$ The activity monitor will be attached to the participant's non-affected thigh and will remain in place for 7 days at each assessment time (6 full days of data). To allow for continuous 24-hour monitoring the participant, under remote instruction from the assessor, will tape the activity monitor inside a zip-lock bag affixed to the skin with a water-proof medical dressing.

The activity monitor will also provide data for secondary analysis of the number of daily steps, and minutes of moderate and vigorous physical activity using a threshold of 75 steps/min, suitable for older adults with mobility limitations. ${ }^{250}$ Sedentary behaviour will be expressed as daily time spent sitting or lying.

\section{Secondary outcome measures}

Secondary outcomes, described in table 2, include measures of psychological-related function (Modified Falls Efficacy Scale, ${ }^{51}$ Ambulatory Self-Confidence Questionnaire $^{52}$ and Depression Anxiety and Stress Scale ${ }^{38}$ ); mobility-related function (de Morton Mobility Index ${ }^{53}$ ); community participation (Frenchay Activities Index, ${ }^{33} 54$ an outdoor participation questionnaire ${ }^{33}$ ); health-related quality of life (Assessment of Quality of Life Instrument (AQoL) 8-D ${ }^{55}$ and ICEpop CAPability measure for older people $\left(\right.$ ICECAP-O $\left.{ }^{56}\right)$ ); falls; ${ }^{57}$ and healthcare utilisation and cost data (daily falls calendar, monthly phone calls, health utilisation questionnaire, health service database (hospital admissions) and Medicare Australia (for services and pharmaceuticals covered by the Medical Benefits Schedule and the Pharmaceutical Benefits Schedule)).

Other data including age, sex, weight, height, hip fracture classification, date and type of surgery, comorbidities, cognitive status, ${ }^{39}$ preinjury status (eg, walking status and social support), nutritional status ${ }^{58}$ and social situation will be recorded at baseline, and any change in weight, nutritional status and social situation recorded at 26 and 52 weeks. Adverse events (categorised as serious or non-serious) will be identified through trial assessments, including records kept by participants (falls calendar) and monthly follow-up phone calls.

\section{Qualitative data}

In-depth semistructured interviews with a purposively selected subgroup of participants in the motivational interviewing group will be completed at weeks 9,16 or 
Table 2 Outcome measures

\begin{tabular}{lllllll}
\hline Outcome & Measure & Description & Administration & Week 0 & Week 9 & Week 26 Week 52 \\
\hline $\begin{array}{l}\text { Primary } \\
\text { Walking }\end{array}$ & $\begin{array}{l}\text { Daily time spent } \\
\text { walking }\end{array}$ & $\begin{array}{l}\text { Daily minutes } \\
\text { spent walking }\end{array}$ & $\begin{array}{l}\text { Tri-axial } \\
\text { accelerometer, } 6 \times 24 \\
\text { hour data }\end{array}$ & $\checkmark$ & $\checkmark$ & $\checkmark$ \\
Secondary & & & & & $\checkmark$
\end{tabular}

\begin{tabular}{|c|c|c|c|c|c|c|c|}
\hline \multirow[t]{2}{*}{ Psychological } & $\begin{array}{l}\text { Modified Falls } \\
\text { Efficacy Scale }\end{array}$ & $\begin{array}{l}\text { 14-item scale, } \\
\text { confidence related } \\
\text { to completing } \\
\text { physical activity } \\
\text { during daily living } \\
\text { tasks without } \\
\text { falling }\end{array}$ & $\begin{array}{l}\text { Questionnaire, self- } \\
\text { report }\end{array}$ & $\checkmark$ & $\checkmark$ & $\checkmark$ & $\checkmark$ \\
\hline & $\begin{array}{l}\text { Depression } \\
\text { Anxiety and } \\
\text { Stress Scale }\end{array}$ & $\begin{array}{l}\text { 21-item scale, } \\
\text { mental health } \\
\text { (depression, } \\
\text { anxiety and stress) }\end{array}$ & $\begin{array}{l}\text { Questionnaire, self- } \\
\text { report }\end{array}$ & $\checkmark$ & $\checkmark$ & $\checkmark$ & $\checkmark$ \\
\hline
\end{tabular}

\begin{tabular}{|c|c|c|c|c|c|c|c|}
\hline Mobility/walking & $\begin{array}{l}\text { De Morton } \\
\text { Mobility Index } \\
\text { (for face-to-face } \\
\text { visits only) }\end{array}$ & $\begin{array}{l}\text { 15-item } \\
\text { unidimensional } \\
\text { measure of } \\
\text { mobility }\end{array}$ & Clinician observation & $\checkmark$ & $\checkmark$ & $\checkmark$ & $\checkmark$ \\
\hline $\begin{array}{l}\text { Sedentary } \\
\text { behaviour }\end{array}$ & $\begin{array}{l}\text { Daily time sitting/ } \\
\text { lying }\end{array}$ & $\begin{array}{l}\text { Daily time sitting/ } \\
\text { lying }\end{array}$ & $\begin{array}{l}\text { Tri-axial } \\
\text { accelerometer 24- } \\
\text { hour wear for } 7 \text { days }\end{array}$ & $\checkmark$ & $\checkmark$ & $\checkmark$ & $\checkmark$ \\
\hline $\begin{array}{l}\text { Community } \\
\text { participation }\end{array}$ & $\begin{array}{l}\text { Participation } \\
\text { Questionnaire }\end{array}$ & $\begin{array}{l}\text { Questions re walk } \\
\text { outdoors alone } \\
\text { or with company, } \\
\text { and frequency of } \\
\text { outdoor walks }\end{array}$ & $\begin{array}{l}\text { Questionnaire, self- } \\
\text { report }\end{array}$ & $\checkmark$ & $\checkmark$ & $\checkmark$ & $\checkmark$ \\
\hline Quality of life & AQoL-8D & $\begin{array}{l}\text { 35-items, } 8 \\
\text { dimensions of } \\
\text { quality of life. }\end{array}$ & $\begin{array}{l}\text { Questionnaire, self- } \\
\text { report }\end{array}$ & $\checkmark$ & $\checkmark$ & $\checkmark$ & $\checkmark$ \\
\hline
\end{tabular}


Table 2 Continued

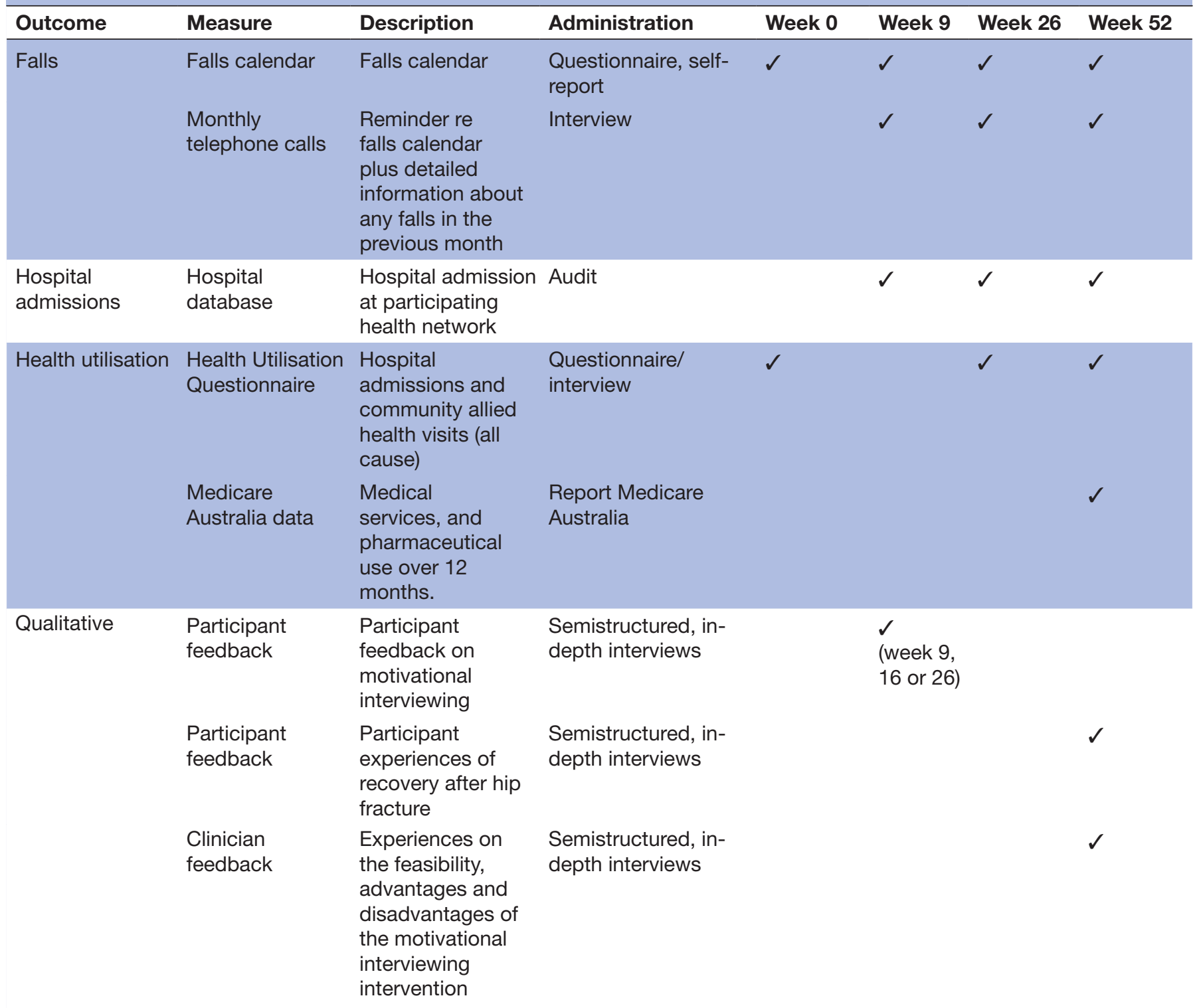

AQoL, Assessment of Quality of Life Instrument.

26, and interviews with a subgroup of participants in both groups will be completed at week 52. Interviews at weeks 9, 16 or 26 will explore perceptions about receiving the motivational interviewing intervention. These interviews are timed to reduce issues related to recall of receiving the intervention. Interviews at week 52 will explore experiences of rehabilitation and recovery of mobility. Participants will be purposively sampled with regards to sex, age and recruitment site. Data collection will continue until data saturation is achieved. Approximately 20-30 intervention participants will be invited to participate in a 30-40 min semistructured telephone interview. In addition, as part of the process evaluation, all allied health professionals who delivered the motivational interviewing intervention will be invited to be interviewed to share their experiences on the feasibility, advantages and disadvantages of the intervention. It is estimated that six to eight allied health professionals may provide the motivational interviewing intervention throughout the project. Audio files of interviews will be transcribed. Participants will receive a written transcript of their interview prior to analysis to have the opportunity to review and add to their responses.

\section{Data analysis}

Sample size estimation

To detect a clinically relevant difference in the primary outcome (daily time spent walking) of $15 \mathrm{~min},{ }^{15} 270$ participants will be required, assuming a conservative SD of $40.4 \mathrm{~min} / \mathrm{day}^{37}$ at power of $80 \%$, two-tailed alpha level of $5 \%$ and attrition of approximately $15 \% .^{59}$ This sample will have $>90 \%$ power to detect a clinically relevant difference $^{60}$ in the number of daily steps taken, estimated from the standardised mean difference of 0.5 in our pilot 
study. ${ }^{34}$ The trial will also be sufficiently powered $(>90 \%)$ to detect clinically relevant changes (standardised mean difference $>0.5)^{60}$ in secondary outcomes of psychological-related function, mobility-related function and quality of life. ${ }^{37}$ Assuming a rate of one fall per year in the control group and a $30 \%$ reduction in falls in the treatment group (incidence rate ratio $=0.7$ ), this sample size is powered at approximately $77 \%$ to detect a difference at the $5 \%$ level using negative binomial regression to account for multiple falls and over-dispersion.?

\section{Data analysis plan}

The primary outcome (daily time spent walking at 12 months) will be analysed using linear mixed effects models. Modelling will account for variation in baseline values and participant sex, consistent with observations of sex differences in physical activity after hip fracture. ${ }^{27}$ This method accounts for within-participant dependence of observations over time, and for missing data, allowing some participants to have missing observations at certain time points. If $>5 \%$ of data are missing, a multiple imputation process will be used, providing the assumption data are missing at random is met. A similar approach will be used for analysis of secondary outcomes collected longitudinally. The time spent in moderate to vigorous physical activity will be estimated using cutoff for moderate-intensity physical activity of 75 steps/ min. ${ }^{50}$ The proportion of participants meeting physical activity guidelines for older people ${ }^{20}$ and the number who fall will be reported as risk ratios. A longitudinal mixed effects logistic regression model will also be used to model the effectiveness of intervention on meeting physical activity guidelines over time. The number of falls and hospital admissions will be reported as an incidence rate ratio and modelled using a negative binomial mixed effects regression model. Risk ratios will be calculated to compare the proportion of participants meeting participation targets. ${ }^{33}$ Instrumental variable regression will be used to estimate the complier average causal effect on the primary outcome, ${ }^{61}$ with participants considered to have adhered if they completed at least eight motivational interviewing sessions. To avoid bias and to maximise the randomisation process, all available data will be analysed according to allocation (intention to treat analysis), regardless of compliance. Model residual diagnostics will be assessed to check for violations and data transformations and/or non-parametric methods will be used when appropriate.

The health economic analysis is a cost effectiveness analysis from a healthcare system perspective, with effectiveness outcomes based on the primary clinical outcome (daily time spent walking) and the secondary outcome of health-related quality of life using the AQoL-8D instrument. The control group is an attention placebo control, and in line with economic evaluations of other placebocontrol trials there will be no programme delivery costs attributed to the control group. Programme delivery costs associated with the intervention will be attributed to the experimental group. Resources costed for the intervention group will include staff (time spent on programme training and delivery by hourly rate using publicly available fee schedules), phone calls and capital (building using rental method and equipment using replacement method). A total intervention cost for each participant in the experimental group will be determined. Total costs for each participant will be determined from the cost of intervention and cost of health services used over 12 months for experimental group participants and the cost of health services used over 12 months for control group participants. Health service utilisation will be determined from the health resource use questionnaire, falls entries and Medicare Australia. Costs will be attributed using schedule price lists. The incremental cost effectiveness ratio around the primary outcome will be calculated as the difference in total programme and health service costs per mean difference in time spent walking/day between the control and experimental groups over 12 months. A cost utility ratio will be calculated based on the secondary outcome measure (AQoL-8D) as the change in total programme and health service cost per change in qualityadjusted life year saved in the experimental and control groups over 12 months. One-way sensitivity analyses will investigate the robustness of the cost effectiveness ratio to a range of cost and effect estimates. On the cost side, this may include alternative delivery arrangements, including scaling up the intervention, wage rates and programme length; on the effect side health-related quality of life and daily time spent walking.

Process evaluation will assess intervention fidelity, explore causal mechanisms and identify factors associated with variation in outcomes. The process evaluation framework can be viewed in figure $3{ }^{62}$ Mediation analysis will explore whether increased walking is mediated through the effect of motivational interviewing on psychological factors such as confidence. ${ }^{63}$ Qualitative data will be analysed using an inductive thematic approach and based on the interpretive descriptive theoretical framework. ${ }^{64}$ Using qualitative software to help manage data (NVivo QSR International, Melbourne), codes will be assigned to text independently by two assessors. Codes will be organised into categories and emergent themes. Methods to enhance rigour and trustworthiness of the qualitative analysis will include member checking and the use of verbatim quotations. ${ }^{65}$

\section{Patient and public involvement}

A member of the public with lived experience of hip fracture joined the trial steering committee after funding for the trial had been approved and the research questions and outcome measures had been developed. This person provided advice on wording, when introducing the research to potential participants, and assisted with assessing the burden of assessment and time required to participate in the research. This person will provide advice on the best ways to disseminate the trial results to participants and to the wider community. The 


\section{Contextual factors}

Motivational Interviewing (MI) has been shown to be effective at increasing walking among community-dwelling older adults after hip fracture. This change might be mediated by an increase in self-efficacy (confidence in walking). MI can increase self-efficacy through MI spirit (partnership, acceptance, compassion, and evocation) and the use of reflections, affirmations, and ability questions (confidence ruler). However, MI is often not implemented as intended, which might affect its efficacy. There are also multiple external factors that shape the intervention and the outcome of the trial, and these will be gleaned through qualitative methods such as interviews with the practitioners, participants and relevant

\begin{tabular}{|c|c|c|c|}
\hline $\begin{array}{l}\text { Description of } \\
\text { intervention and its } \\
\text { causal assumptions } \\
8 \text { weekly MI sessions via } \\
\text { telephone and } 2 \text { booster } \\
\text { sessions } \\
\text { Assumptions: } \\
\text { - Ml is delivered as intended } \\
\text { - MI will produce change } \\
\text { mediated through self- } \\
\text { efficacy } \\
\text { - No implementation issues } \\
\text { in the trial which affect the } \\
\text { outcome independent of the } \\
\text { intervention }\end{array}$ & $\begin{array}{l}\text { Implementation } \\
\text { Was the intervention and } \\
\text { control delivered as intended? } \\
\text { E.g. Did the participant } \\
\text { receive the planned number } \\
\text { and duration of sessions } \\
\text { (dose)? What was the quality } \\
\text { of the delivered intervention } \\
\text { (fidelity)? } \\
\text { Data source: } \\
\text { - Audiotapes of sessions } \\
\text { • Clinician records } \\
\text { - Fidelity assessed by MITI } \\
4.2 .1\end{array}$ & $\begin{array}{l}\text { Mechanism of Impact } \\
\text { How did the intervention } \\
\text { produce change? } \\
\text { E.g. Is self-efficacy a mediator } \\
\text { of MI in producing change in } \\
\text { walking? How does the } \\
\text { participant respond to MI? } \\
\text { Are there any issues } \\
\text { identified in implementation? } \\
\text { Data source: } \\
\text { - Interview with participant at } \\
\text { week } 9,16, \text { or } 26 \\
\text { - Quantitative mediation } \\
\text { analysis }\end{array}$ & $\begin{array}{c}\text { Outcome } \\
\text { - Increased } \\
\text { mobility } \\
\text { (walking) at } 12 \\
\text { months (primary } \\
\text { outcome) } \\
\text { - Increased } \\
\text { Quality of Life } \\
\text { - Reduced falls }\end{array}$ \\
\hline
\end{tabular}

Figure 3 Process evaluation framework for MIHip trial. MIHip, motivational interviewing after hip fracture; MITI, Motivational Interviewing Integrity Scale.

governance structure of the trial comprises a project steering committee; and a data monitoring committee, which comprises a chair from the research team and two independent expert clinicians from participating health networks.

\section{Ethics and dissemination}

Ethical approval was granted by health network and university ethics committees before the trial started. Owing to the inclusion criteria participants will be competent to provide their own written consent to participate.

The findings from this trial will be disseminated through peer-reviewed journal publications, conference presentations and through public seminars. Clinicians and participants will be informed of the trial's progress through a quarterly newsletter. Consistent with Australian National Health and Medical Research Council policies, data from the trial will be available through OPAL, La Trobe University's Institutional Repository or through online supplemental data files accompanying publication of findings.

Hip fractures are a major health burden for older adults and are of increasing importance with an ageing population. Improving physical activity by improving psychological-related function and walking are key to improving health, relieving the burden on those who experience hip fracture, their carers and society. Current rehabilitation models do not address lack of confidence, a core barrier to walking in older adults after hip fracture.
Our trial will provide evidence of whether motivational interviewing can help people live independently in the community after hip fracture.

\section{Trial status}

Enrolment for the trial began in September 2019 and is still in progress. Data collection will continue until early to middle 2022.

Author affiliations

${ }^{1}$ La Trobe University College of Science Health and Engineering, Bundoora, Victoria, Australia

${ }^{2}$ Allied Health Clinical Research Office, Eastern Health, Box Hill, Victoria, Australia ${ }^{3}$ School of Health \& Social Development, Faculty of Health, Deakin University, Burwood, Victoria, Australia

${ }^{4}$ College of Science Health and Engineering, La Trobe University - Bundoora Campus, Melbourne, Victoria, Australia

${ }^{5}$ Institute for Physical Activity and Nutrition (IPAN), Deakin University School of Exercise and Nutrition Sciences, Geelong, Victoria, Australia

${ }^{6}$ Peninsula Clinical School, Central Clinical School, Monash University, Frankston, Victoria, Australia

${ }^{7}$ Academic Unit, Peninsula Health, Frankston, Victoria, Australia

${ }^{8}$ Rehabilitation, Ageing and Independent Living (RAIL) Research Centre, School of Primary and Allied Health Care, Monash University, Clayton, Victoria, Australia ${ }^{9}$ Emergency and Trauma Centre, Alfred Health, Melbourne, Victoria, Australia

${ }^{10}$ Department of Orthopaedics and Surgery, Eastern Health, Box Hill, Victoria, Australia

Twitter Nicholas F Taylor @EH_Research and Nora Shields @DrNoraShields

Contributors NFT, PO'H, JJW and NS: designed the trial, led acquisition of funding, drafting and critical revision of the manuscript. RM: contributed substantially as the trial coordinator, drafting and critical revision of the manuscript. CP: contributed to 
trial design (physical activity assessment) and critical revision of this manuscript. JP: contributed to trial design (dietary education) and critical revision of the manuscript. LP: contributed to trial design (statistical analysis plan) and critical revision of the manuscript. KEH: contributed to trial design, trial conduct at one site and critical revision of the manuscript. DAS and CLE: responsible for the conduct of the trial at one site and critical revision of the manuscript. $\mathrm{RH}$ : responsible for the Data Monitoring Committee and critical revision of the manuscript. SBM: contributed to the health economic component of the trial design and critical evaluation of the manuscript. MUR: contributed as a research student (process evaluation) and critical revision of the manuscript. KN: contributed as a site coordinator and critical revision of the manuscript. MS and DK: contributed as a research officer at one site and critical evaluation of the manuscript.

Funding This project is supported by Australian National Health and Medical Research Council (NHMRC) project grant number 1157 529. MUR is supported by a La Trobe Graduate Research Scholarship (no grant number).

Competing interests None declared.

Patient consent for publication Not required.

Provenance and peer review Not commissioned; peer reviewed for ethical and funding approval prior to submission.

Supplemental material This content has been supplied by the author(s). It has not been vetted by BMJ Publishing Group Limited (BMJ) and may not have been peer-reviewed. Any opinions or recommendations discussed are solely those of the author(s) and are not endorsed by BMJ. BMJ disclaims all liability and responsibility arising from any reliance placed on the content. Where the content includes any translated material, BMJ does not warrant the accuracy and reliability of the translations (including but not limited to local regulations, clinical guidelines, terminology, drug names and drug dosages), and is not responsible for any error and/or omissions arising from translation and adaptation or otherwise.

Open access This is an open access article distributed in accordance with the Creative Commons Attribution Non Commercial (CC BY-NC 4.0) license, which permits others to distribute, remix, adapt, build upon this work non-commercially, and license their derivative works on different terms, provided the original work is properly cited, appropriate credit is given, any changes made indicated, and the use is non-commercial. See: http://creativecommons.org/licenses/by-nc/4.0/.

\section{ORCID iDs}

Nicholas F Taylor http://orcid.org/0000-0001-9474-2504

Paul D 0'Halloran http://orcid.org/0000-0001-6495-2359

Jennifer J Watts http://orcid.org/0000-0001-8095-8638

Casey L Peiris http://orcid.org/0000-0002-0686-7436

Judi Porter http://orcid.org/0000-0002-7535-1919

Luke A Prendergast http://orcid.org/0000-0002-9122-5429

Katherine E Harding http://orcid.org/0000-0003-0207-7071

David A Snowdon http://orcid.org/0000-0003-2041-3120

Christina L Ekegren http://orcid.org/0000-0002-7656-6209

Raphael Hau http://orcid.org/0000-0002-7380-7812

Shalika B Mudiyanselage http://orcid.org/0000-0003-1090-4401

Nora Shields http://orcid.org/0000-0002-6840-2378

\section{REFERENCES}

1 Watts JJ, Abimanyi-Ochom J, Sanders KM. Osteoporosis costing all Australian: a new burden of disease analysis-2012 to 2022. Glebe: Osteoporosis Australia, 2013.

2 Beringer TRO, Clarke J, Elliott JRM, et al. Outcome following proximal femoral fracture in Northern Ireland. Ulster Med $\mathrm{J}$ 2006;75:200-6.

3 March LM, Cameron ID, Cumming RG, et al. Mortality and morbidity after hip fracture: can evidence based clinical pathways make a difference? J Rheumatol 2000;27:2227-31.

4 Le Manach Y, Collins G, Bhandari M, et al. Outcomes after hip fracture surgery compared with elective total hip replacement. JAMA 2015;314:1159-66.

5 Koval KJ, Zuckerman JD. Functional recovery after fracture of the hip. J Bone Joint Surg Am 1994;76:751-8.

6 Nevalainen TH, Hiltunen LA, Jalovaara P. Functional ability after hip fracture among patients home-dwelling at the time of fracture. Cent Eur J Public Health 2004;12:211-6.

7 Lloyd BD, Williamson DA, Singh NA, et al. Recurrent and injurious falls in the year following hip fracture: a prospective study of incidence and risk factors from the sarcopenia and hip fracture study. J Gerontol A Biol Sci Med Sci 2009;64:599-609.

8 Taylor NF, Barelli C, Harding KE. Community ambulation before and after hip fracture: a qualitative analysis. Disabil Rehabil 2010;32:1281-90.

9 Dennett AM, Taylor NF, Mulrain K. Community ambulation after hip fracture: completing tasks to enable access to common community venues. Disabil Rehabil 2012;34:707-14.

10 Mak JCS, Cameron ID, March LM, et al. Evidence-Based guidelines for the management of hip fractures in older persons: an update. Med J Aust 2010;192:37-41.

11 National Institute for Health and Care Excellence. Hip fracture: management. clinical guideline CG124. London: NICE, 2017.

12 Taylor NF, Harding KE, Dowling J, et al. Discharge planning for patients receiving rehabilitation after hip fracture: a qualitative analysis of physiotherapists' perceptions. Disabil Rehabil 2010;32:492-9.

13 Handoll HH, Sherrington C, Mak JC. Interventions for improving mobility after hip fracture surgery in adults. Cochrane Database Syst Rev 2011;001704:CD001704.

14 Lee I-M, Shiroma EJ, Lobelo F, et al. Effect of physical inactivity on major non-communicable diseases worldwide: an analysis of burden of disease and life expectancy. Lancet 2012;380:219-29.

15 Wen CP, Wai JPM, Tsai MK, et al. Minimum amount of physical activity for reduced mortality and extended life expectancy: a prospective cohort study. Lancet 2011;378:1244-53.

16 Peiris C, Shields N, Kingsley M, et al. Maximum tolerated dose of walking for community-dwelling people recovering from hip fracture: a dose-response trial. Arch Phys Med Rehabil 2017;98:2533-9.

17 Taylor NF, Peiris CL, Kennedy G, et al. Walking tolerance of patients recovering from hip fracture: a phase I trial. Disabil Rehabil 2016;38:1900-8.

18 Das P, Horton R. Physical activity-time to take it seriously and regularly. Lancet 2016;388:1254-5.

19 Cadilhac DA, Cumming TB, Sheppard L, et al. The economic benefits of reducing physical inactivity: an Australian example. Int J Behav Nutr Phys Act 2011;8:99.

20 World Health Organization. WHO guidelines on physical activity and sedentary behaviour. Geneva: WHO, 2020.

21 Zusman EZ, Dawes MG, Edwards N, et al. A systematic review of evidence for older adults' sedentary behavior and physical activity after hip fracture. Clin Rehabil 2018;32:679-91.

22 Davenport SJ, Arnold M, Hua C, et al. Physical activity levels during acute inpatient admission after hip fracture are very low. Physiother Res Int 2015;20:174-81.

23 Peiris CL, Taylor NF, Shields N. Patients receiving inpatient rehabilitation for lower limb orthopaedic conditions do much less physical activity than recommended in guidelines for healthy older adults: an observational study. J Physiother 2013;59:39-44.

24 Resnick B, Galik E, Boltz M, et al. Physical activity in the post-hipfracture period. J Aging Phys Act 2011;19:373-87.

25 Tudor-Locke C, Camhi SM, Leonardi C, et al. Patterns of adult stepping cadence in the 2005-2006 NHANES. Prev Med 2011;53:178-81.

26 Lee I-M, Shiroma EJ, Kamada M, et al. Association of step volume and intensity with all-cause mortality in older women. JAMA Intern Med 2019;179:1105-12.

27 Fleig L, McAllister MM, Brasher P, et al. Sedentary behavior and physical activity patterns in older adults after hip fracture: a call to action. J Aging Phys Act 2016;24:79-84.

28 Taylor NF, Peiris CL, Thompson AL, et al. Association between physical activity and short-term physical function changes after hip fracture: an observational study. Physiother Res Int 2021;26:e1876.

29 Rodaro E, Pasqualini M, Iona LG, et al. Functional recovery following a second hip fracture. Eura Medicophys 2004;40:179-83.

30 Oude Voshaar RC, Banerjee S, Horan M, et al. Fear of falling more important than pain and depression for functional recovery after surgery for hip fracture in older people. Psychol Med 2006;36:1635-45.

31 Lord SE, Weatherall M, Rochester L. Community ambulation in older adults: which internal characteristics are important? Arch Phys Med Rehabil 2010;91:378-83.

32 Proctor R, Wade R, Woodward Y, et al. The impact of psychological factors in recovery following surgery for hip fracture. Disabil Rehabil 2008;30:716-22.

33 Zidén L, Frändin K, Kreuter M. Home rehabilitation after hip fracture. A randomized controlled study on balance confidence, physical function and everyday activities. Clin Rehabil 2008;22:1019-33.

34 Miller WR, Rollnick S. Motivational interviewing: helping people change. 3rd edn. NY: Guildford Press, 2012. 
35 Rubak S, Sandbaek A, Lauritzen T, et al. Motivational interviewing: a systematic review and meta-analysis. $\mathrm{Br} J$ Gen Pract 2005;55:305-12.

36 O'Halloran PD, Blackstock F, Shields N, et al. Motivational interviewing to increase physical activity in people with chronic health conditions: a systematic review and meta-analysis. Clin Rehabil 2014;28:1159-71.

37 O'Halloran PD, Shields N, Blackstock F, et al. Motivational interviewing increases physical activity and self-efficacy in people living in the community after hip fracture: a randomized controlled trial. Clin Rehabil 2016;30:1108-19.

38 Gloster AT, Rhoades HM, Novy D, et al. Psychometric properties of the depression anxiety and stress Scale-21 in older primary care patients. J Affect Disord 2008;110:248-59.

39 Pfeiffer E. A short portable mental status questionnaire for the assessment of organic brain deficit in elderly patients. J Am Geriatr Soc 1975;23:433-41.

40 Physical Activity Australia. Exercise pre-screening questionnaire. Port Melbourne: Physical Activity Australia, 2020. https://www.physical activityaustralia.org.au/wp-content/uploads/2016/09/Pre-ExerciseScreening-Form.pdf

41 DiClemente CC, Velasquez MM. Miller WR, Rollnick S, eds. Motivational interviewing and the stages of change.Book chapter in motivational interviewing: preparing people for change. NY: Guilford Press, 2002: 201-16.

42 Markland D, Ryan RM, Tobin VJ, et al. Motivational interviewing and self-determination theory. J Soc Clin Psychol 2005;24:811-31.

43 Morton K, Beauchamp M, Prothero A, et al. The effectiveness of motivational interviewing for health behaviour change in primary care settings: a systematic review. Health Psychol Rev 2015:9:205-23.

44 Moyers TB, Rowell LN, Manuel JK, et al. The motivational interviewing treatment integrity code (MITI 4): rationale, preliminary reliability and validity. J Subst Abuse Treat 2016;65:36-42.

45 Eneroth M, Olsson U-B, Thorngren K-G. Insufficient fluid and energy intake in hospitalised patients with hip fracture. A prospective randomised study of 80 patients. Clin Nutr 2005;24:297-303.

46 Breedveld-Peters JJL, Reijven PLM, Wyers CE, et al. Integrated nutritional intervention in the elderly after hip fracture. A process evaluation. Clin Nutr 2012;31:199-205.

47 Latham NK, Harris BA, Bean JF, et al. Effect of a home-based exercise program on functional recovery following rehabilitation after hip fracture: a randomized clinical trial. JAMA 2014;311:700-8.

48 Grant PM, Dall PM, Mitchell SL, et al. Activity-monitor accuracy in measuring step number and cadence in community-dwelling older adults. J Aging Phys Act 2008;16:201-14.

49 Peiris CL, Taylor NF, Shields N. Additional Saturday allied health services increase habitual physical activity among patients receiving inpatient rehabilitation for lower limb orthopedic conditions: a randomized controlled trial. Arch Phys Med Rehabil 2012:93:1365-70.

50 Tudor-Locke C, Han H, Aguiar EJ, et al. How fast is fast enough? Walking cadence (steps/min) as a practical estimate of intensity in adults: a narrative review. Br J Sports Med 2018;52:776-88.

51 Edwards N, Lockett D. Development and validation of a modified falls-efficacy scale. Disabil Rehabil Assist Technol 2008;3:193-200.

52 Asano M, Miller WC, Eng JJ. Development and psychometric properties of the ambulatory self-confidence questionnaire. Gerontology 2007;53:373-81.

53 de Morton NA, Harding KE, Taylor NF, et al. Validity of the de Morton mobility index (DEMMI) for measuring the mobility of patients with hip fracture during rehabilitation. Disabil Rehabil 2013;35:325-33.

54 Turnbull JC, Kersten P, Habib M, et al. Validation of the Frenchay activities index in a general population aged 16 years and older. Arch Phys Med Rehabil 2000;81:1034-8.

55 Richardson JIA. Psychometric validity and the AQoL-8D multi attribute utility instrument. Melbourne: Centre for Health Economics, Monash University, 2011.

56 Makai P, Koopmanschap MA, Brouwer WB, et al. A validation of the ICECAP-O in a population of post-hospitalized older people in the Netherlands. Health Qual Life Outcomes 2013;11:57.

57 Lamb SE, Jørstad-Stein EC, Hauer K, et al. Development of a common outcome data set for fall injury prevention trials: the prevention of falls network Europe consensus. J Am Geriatr Soc 2005;53:1618-22.

58 Leipold CE, Bertino SB, L'Huillier HM, et al. Validation of the malnutrition screening tool for use in a community rehabilitation program. Nutr Diet 2018;75:117-22.

59 Zidén L, Kreuter M, Frändin K. Long-term effects of home rehabilitation after hip fracture - 1-year follow-up of functioning, balance confidence, and health-related quality of life in elderly people. Disabil Rehabil 2010;32:18-32.

60 Norman GR, Sloan JA, Wyrwich KW. Interpretation of changes in health-related quality of life: the remarkable universality of half a standard deviation. Med Care 2003;41:582-92.

61 Shrier I, Steele RJ, Verhagen E, et al. Beyond intention to treat: what is the right question? Clin Trials 2014;11:28-37.

62 Moore GF, Audrey S, Barker M, et al. Process evaluation of complex interventions: medical Research Council guidance. BMJ 2015;350:h1258.

63 Preacher KJ, Hayes AF. SPSS and SAS procedures for estimating indirect effects in simple mediation models. Behav Res Methods Instrum Comput 2004;36:717-31.

64 Thompson Burdine J, Thorne S, Sandhu G. Interpretive description: a flexible qualitative methodology for medical education research. Med Educ 2021;55:336-43.

65 Krefting L. Rigor in qualitative research: the assessment of trustworthiness. Am J Occup Ther 1991;45:214-22. 